\title{
VIDEOCONFERENCIA, COOPERACIÓN JUDICIAL INTERNACIONAL Y DEBIDO PROCESO
}

\section{VIDEOCONFERÊNCIA, COOPERACÃO JUDICIAL INTERNACIONAL E DEVIDO PROCESSO}

Jesús José Tirado Estrada

Resumen: El presenteartículoacometeunaaproximaciónalascaracterísticas, utilidad y empleo de la videoconferencia como herramienta tecnológica de auxilio a la actividad procesal del sistema de impartición de Justicia Penal $y$ su reconocimiento normativo tanto en ordenamientos internos como en instrumentos internacionales de cooperación judicial internacional europeos e iberoamericanos. Asimismo, se trata su compatibilidad con las exigencias y garantías derivadas del respeto al derecho fundamental al debido proceso. Resumo: $O$ presente artigo acomete uma aproximação às características, utilidade e emprego da videoconferência como ferramenta tecnológica de auxílio à atividade processual do sistema de impartição de Justiça Penal e seu reconhecimento normativo tanto em ordenamentos internos como em instrumentos internacionais de cooperação judicial internacional europeus e iberoamericanos. Assim mesmo trata-se sua compatibilidade com as exigências e garantias derivadas do respeito ao direito fundamental ao devido processo.

Palabras clave: Videoconferencia, Auxilio judicial internacional, Debido proceso, Penal

Palavras-chave: Videoconferência, Auxilio judicial internacional, Devido processo, Penal

\section{CONSIDERACIONES INICIALES}

La introducción de nuevas tecnologías en la actividad de la Administración de Justicia conlleva una cierta revolución de los modos de trabajo de los órganos implicados en la prestación del servicio público

\footnotetext{
* Teniente Fiscal ante el Tribunal Constitucional, España.

E-mail: jesus.tirado@fiscal.es

Recibido: 09/08/2017. Aceptado: 29/09/2017.
} 
que están llamados a asegurar. Juzgados, Tribunales y Fiscalías asisten en los últimos años a una profunda renovación material y conceptual de sus tareas, y ello afecta a la mentalidad tradicional con la que se han venido ejecutando. Los nuevos instrumentos determinan nuevas problemáticas y frecuentemente la ley tarda en adaptar sus preceptos a las aportaciones que aquellos posibilitan. Incluso cuando existe una previsión normativa nacida con la pretensión de dar cobertura a las innovaciones presentes y futuras, se acaba discutiendo si el "nuevo invento" de última generación es admisible o no, e incluso, obviando su utilidad para la optimización de los medios disponibles y las tareas a realizar, se polemiza sobre si su incorporación es posible o no al "status quo" con el que se está acostumbrado a trabajar.

Tal podría ser el caso de la discusión surgida en algún caso sobre el uso de la videoconferencia en el proceso penal, si bien en la actualidad, tras algún periodo de empleo en la práctica sin cobertura legal específica, es ya un recurso consolidado en numerosos ordenamientos internos y una herramienta de cooperación judicial internacional reconocida en importantes convenios regionales.

Pero antes de seguir adelante es necesario concretar a qué estamos aludiendo cuando estamos hablando de este instrumento tecnológico y precisar cuál es el abanico de posibilidades que proporciona la videoconferencia.

La videoconferencia consiste básicamente en un sistema interactivo de comunicación que transmite simultáneamente y "en tiempo real" la imagen, el sonido y los datos a distancia (en conexión punto a punto), permitiendo relacionar e interactuar, visual, auditiva y verbalmente, a un grupo de personas situadas en dos o más lugares distintos como si la reunión y el diálogo se sostuviese en el mismo lugar. En definitiva, mediante la videoconferencia se conectan entre sí varios puntos distantes. En cada punto se sitúa un equipo que transmite la imagen y el sonido del acto que se está practicando y que, al mismo tiempo, recibe en un monitor de alta resolución la imagen y el sonido de lo que está ocurriendo en el otro punto. Con ello se permite una comunicación bidireccional plena en tiempo real en el que el efecto es un "acto" o "reunión" al que asisten personas que se encuentran en lugares diferentes. La comunicación puede producirse en condiciones excelentes de seguridad, celeridad y calidad gracias a la encriptación y a la elevada capacidad de los canales de transmisión que se utilizan. Los equipos de videoconferencia disponen de múltiples funciones que permiten su adaptación a las diferentes necesidades que sean impuestas en la práctica de los distintos actos procesales: tomas completas de la sala, selección de la imagen de la persona que toma la palabra o de un grupo de personas, seguimiento automático de movimientos o desplazamientos en la sala, distintas definiciones del ángulo de la cámara, acercar/alejar 
a través de un zoom extraordinariamente versátil que permite incluso la visualización de documentos, adaptación a las distintas condiciones de luminosidad, control remoto de la cámara ubicada en el otro punto, etc. Las operaciones se pueden realizar de forma muy sencilla mediante el manejo de controles tanto de la cámara situada en la sala de dirección como de las instaladas en los lugares remotos.

\section{CAMPO DE ACCIÓN, MOTIVOS, EMPLEO Y RECONOCIMIENTO NORMATIVO EN LOS ORDENAMIENTOS NACIONALES}

La praxis revela que el uso de videoconferencias en el sistema penal ha tenido causa preferentemente en razones de seguridad o de imposibilidad o inconveniencia de desplazamiento de víctimas, testigos o peritos, en motivos de ahorro de costes o en necesidades perentorias de celeridad o agilización de determinadas diligencias surgidas tanto en el marco interno como, muy especialmente, en el de la prestación de la ayuda judicial internacional como mecanismo de reacción frente a la proverbial lentitud, el frecuente retraso y la extraordinaria complejidad de la burocracia de la cooperación judicial.

La experiencia comparada e internacional desde la última década del siglo XX confirma la anterior afirmación. Aunque en un primer momento las videoconferencias fueron utilizadas incluso sin cobertura legal, pronto obtuvieron reconocimiento normativo y las razones mencionadas vinieron siendo sido recogidas como causas justificativas de su empleo en las regulaciones internas de Derecho Comparado y en los textos internacionales públicos que prevén su uso.

A nivel de Derecho comparado europeo, en el sistema continental $y$ en el plano de ordenamientos internos, corresponde a Italia el mérito de haber sido el país pionero en materia de regulación y uso de la videoconferencia en el marco del proceso penal, lo que en gran medida vino determinado por la necesidad de uso de este recurso como instrumento irrenunciable en la difícil lucha contra la delincuencia organizada mafiosa. En 1992, ya había sido utilizada en los procesos seguidos por los atentados cometidos contra los magistrados anti-mafia Falcone y Borsalino, pero fue en 1993 cuando una ley institucionalizó su empleo en los procesos contra mafiosos, siendo frecuentemente usada para la audición de testigos ubicados en lugares secretos, con objeto de evitar los riesgos inherentes a su desplazamiento y asistencia a la sala de enjuiciamiento cuando concurrían circunstancias de gran peligrosidad $y$, en general, en casos en los que el proceso requería unas condiciones de intensa seguridad. La Ley $\mathrm{N}^{\circ} 11$ de 7 de enero de 1998 estableció su utilización respecto de detenidos extremamente peligrosos -asegurando el contacto permanente con sus defensores y la sala de audiencia- y en relación con crímenes mafiosos, de asociación de malhechores con fines 
de contrabando y tráfico de drogas, de secuestro de personas con fines de extorsión, con procesos complejos y, en especial, con juicios celebrados en condiciones de peligrosidad intensa. Posteriormente, a raíz del art. 16 de la Ley $\mathrm{n}^{\circ} 367$ de 5 de octubre de 2001 relativa a la ratificación del Acuerdo italo-suizo, se introdujo el artículo 205 ter CPP -disposición aplicable en defecto de acuerdos internacionales- que prevé el uso de la videoconferencia con países extranjeros para la audición de testigos y peritos, así como de inculpados detenidos en el extranjero que no puedan ser transferidos a Italia.

En Francia, el primer paso en la previsión del uso de la videoconferencia en el proceso penal, lo dio la Ley de 17 de enero de 1998 relativa a la delincuencia sexual y a la protección de menores víctimas de delitos. Posteriormente, una Ordenanza de 20 de agosto del mismo año, completada por un Decreto de aplicación de 18 de mayo de 2001 contempló la aplicación de medios audiovisuales para el desarrollo de audiencias civiles o penales en casos de recusación de magistrados de las Islas de Saint Pierre y Miquelon, islas francesas próximas a Canadá. Pero la instauración con carácter general de este medio tuvo lugar mediante la Ley de 15 de noviembre de 2001 que introdujo un nuevo artículo número 706-71- en el Código Procesal Penal francés, que dispuso que "cuando las necesidades de la investigación lo justifiquen, la audición o el interrogatorio de una persona así como la confrontación entre varias personas pueden ser realizadas en distintos puntos del territorio de la República encontrándose conectados por medios de comunicación que garanticen la confidencialidad de la transmisión" y que expresamente contempló que las disposiciones del artículo son aplicables para la ejecución simultánea, sobre un punto del territorio de la República y sobre un punto situado en el exterior, de solicitudes emanadas de autoridades judiciales extranjeras o de actos de cooperación realizados en el extranjero a solicitud de autoridades judiciales francesas.

En Portugal, tanto la Ley de Cooperación Judicial Internacional 144/99, de 31 de agosto, como el Código de Proceso Penal -en sus artículos 317 y 318 en relación con el artículo 111- establecieron la posibilidad de empleo de la videoconferencia. Testigos y peritos en todo caso y encausados, previo consentimiento, pueden prestar sus declaraciones a distancia y en tiempo real a través de "teleconferências" -en el caso de los peritos pertenecientes a establecimientos, laboratorios o servicios especiales desde su propio lugar de trabajo-.

En España, desde la Ley Orgánica 13/2003, de 24 de octubre, de reforma de la Ley de Enjuiciamiento Criminal, existe una regulación interna del uso de la videoconferencia en el proceso penal que se caracteriza por la gran amplitud para su práctica. Amén de prever el artículo 306 LECR la posibilidad de intervención del fiscal en las actuaciones mediante videoconferencia, los artículos. 325, 731 bis LECR, 
en relación con el artículos 229.3 LOPJ, establecieron la posibilidad de que el juez o el tribunal, de oficio o a instancia de parte, por razones de utilidad, seguridad o de orden público, así como en aquellos supuestos en que la comparecencia de quien haya de intervenir en cualquier tipo de procedimiento penal como imputado, testigo, perito, o en otra condición (víctima, responsable civil, partícipe a título lucrativo) resulte gravosa o perjudicial, pueda acordar que la comparecencia se realice a través de videoconferencia u otro sistema similar que permita la comunicación bidireccional y simultánea de la imagen y el sonido, así como la interacción visual, auditiva y verbal entre dos personas o grupos de personas geográficamente distantes, asegurando, eso sí, en todo caso condiciones de contradicción de las partes y de salvaguarda del derecho de defensa ${ }^{1}$.

El uso de la videoconferencia también se ha afianzado en los sistemas de tradición anglosajona y germana, de modo que diversos países contemplan su empleo en el marco de su ordenamiento interno (Australia -Ley 1 de marzo de 1997-, Canadá -a través de la Ley de 17 de junio de 1999-, Estados Unidos -donde habiendo comenzado por las declaraciones de militares destinados en el extranjero, su práctica se extendió a menores víctimas y a testigos de determinados hechos delictivos ${ }^{2}$-, Inglaterra, Irlanda, Islandia, e igualmente su utilización ha sido habitual en Alemania, donde la Corte Constitucional Federal ha resuelto a favor de su utilización).

\section{VIDEOCONFERENCIA Y AUXILIO INTERNACIONAL EN EL PROCESO PENAL. INSTRUMENTOS INTERNACIONALES EUROPEOS E IBEROAMERICANOS}

Las necesidades de empleo de las nuevas tecnologías en general y el recurso a la videoconferencia también han obtenido reconocimiento normativo en el marco del proceso de internacionalización de la

\footnotetext{
1 La mayor singularidad en España de la utilización interna de la videoconferencia frente al uso internacional es la no necesidad del consentimiento de los imputados o responsables de los hechos. El ordenamiento jurídico-penal español no impone restricción alguna salvo las que lógicamente se derivan del respeto al derecho a un proceso con todas las garantías. El uso de la videoconferencia deberá ser especialmente responsable en estos casos y sometido, a exigencias de necesidad, adecuación y proporcionalidad. Otra peculiariedad importante es la atribución de la función de identificación de las personas intervinientes al Secretario Judicial del Juzgado o Tribunal -recientemente redenominado como Letrado de la Administración de Justicia- que haya acordado la medida, sin previsión expresa de intervención de una autoridad similar en la sede física donde se encuentre el compareciente.

2 A pesar de que la VI enmienda planteó ciertas dificultades, éstas fueron superadas en amplios términos. Sin embargo, el Fiscal puede por razones prácticas, de posibilidad o de eficacia del testimonio preferir la presencia física a la audiencia. Los "Ex" Presidentes Ronald Reegan y Bill Clinton han utilizado este medio en sus declaraciones en procesos penales. Reegan en el proceso contra su antiguo Consejero de Seguridad John Poindexter y Clinton ante la Corte Federal de Arkansas en Little Rock en el asunto Whitewater (1996).
} 
coacción penal y en el ámbito del auxilio judicial internacional.

Expresamente, el Estatuto de la Corte Penal Internacional aprobado en Roma el 17 de julio de 1998 contempló en su artículo 69.2 la posibilidad de que el testigo preste testimonio "por medio de una grabación de video o audio" y prevé en su art. 68.2 que con base en razones de protección de víctimas o testigos se presenten pruebas "por medios electrónicos u otros medios especiales". Incluso, respecto de los acusados se admite -art. 63.2- la posibilidad de que, en los casos de los denominados "juicios de ruptura" sala donde se desarrolle el enjuiciamiento, permitiendo que "observe el proceso y de instrucciones a su defensor desde fuera, utilizando, en caso necesario, tecnologías de comunicación", medida que ha sido puesta en práctica especialmente ante la problemática surgida en procesos desarrollados en el ámbito de actuación del Tribunal Internacional para la antigua Yugoslavia.

No obstante, no cabe duda de que el campo donde más se ha propiciado el uso de este instrumento tecnológico ha venido siendo la asistencia judicial internacional en materia penal.

En la Unión Europea, como desarrollo del espacio común de libertad, seguridad y justicia, el Convenio Europeo relativo a la Asistencia Judicial en materia penal entre los Estados miembros de la Unión ${ }^{4}$ reguló la práctica de las videoconferencias en su artículo 10, respecto tanto de testigos y peritos (párrafos 1 a 8), como de acusados (apartado 9), para cuando "no sea oportuno o posible" que la persona que se halla en el territorio de un Estado miembro comparezca en el territorio de otro Estado, cuyas autoridades tengan necesidad de oírla.

De la regulación establecida en este convenio y el Informe Explicativo que constituye su interpretación auténtica oficial ${ }^{5}$ conviene destacar algunas observaciones en torno a los presupuestos necesarios para la solicitud y práctica de la videoconferencia.

El régimen o nivel de obligatoriedad para el Estado requerido de acceder a la solicitud planteada difiere en función de la condición procesal de la persona que ha de ser oída.

\footnotetext{
3 Aquellos en los que el acusados o acusados persisten en perturbar continuamente el desarrollo del juicio.

4 Aprobado el 29 de mayo de 2000 por el Consejo de Ministros de Justicia y Asuntos Exteriores y publicado en el DOCE C 197, de 12 de julio 2000. Una vez abierto a ello, el texto fue firmado de inmediato por todos los Representantes de los Estados miembros de la Unión (afectando también al Anexo A del Acuerdo celebrado por el Consejo de la Unión Europea con Islandia y Noruega sobre la asociación de estos dos Estados a la ejecución, aplicación y desarrollo del acervo de Schengen). Con ello se puso fin a un largo proceso de elaboración de un instrumento apto para dotar a la Europa comunitaria de soluciones modernas y ágiles de cooperación internacional de especial utilidad en materia de obtención y práctica de prueba.

5 Texto aprobado por el Consejo el 30 de noviembre de 2000 (DOCE C 379, de 29 de diciembre de 2000).
} 


\section{A) Si la solicitud se refiere a testigos, víctimas o peritos}

El Estado miembro tiene la obligación imperativa de autorizar la audición por videoconferencia siempre que su uso no sea contrario a los principios fundamentales de su Derecho Nacional y que disponga de los medios técnicos necesarios, aunque este último requisito no tiene por qué funcionar de hecho como motivo de denegación, pues expresamente se prevé que el Estado miembro requirente podrá ponerlos a disposición del requerido sobre la base de un acuerdo entre los Estados implicados. El Informe Explicativo identifica algunas pautas de aproximación a la significación de la referencia a los "principios fundamentales del Derecho nacional" indicando que no podrá ser denegada una solicitud por la mera razón de que en la ley del Estado miembro requerido no se prevea la audición por videoconferencia, o de que, con arreglo a la legislación nacional, no se cumplan una o más condiciones de detalle para realizar dicho tipo de audiciones. La contradicción con los principios fundamentales del Derecho nacional del Estado miembro requerido sí constituye un obstáculo insalvable que fundamenta suficientemente la denegación de la ayuda solicitada; pero el propio informe ubica la cuestión en sus justos términos, obligando a una interpretación claramente referida no a cuestiones de previsión de su uso o de regulación ordinaria de la práctica de la diligencia, sino de auténtica colisión con los principios más esenciales del Estado de Derecho del miembro requerido, entre los que lógicamente estarán implicados los derechos y libertades públicas internacional y nacionalmente reconocidos. Aunque el precepto sólo se refiere a la protección de los derechos humanos y de las libertades públicas en su apartado 9, dedicado a las audiciones de los acusados, es obvio que debe siempre tenerse bien presente la necesidad de velar por los mismos. La vigilancia del respeto a las garantías es, en cada momento, esencial. En el actual estado de la Unión Europea, todos los Estados miembros comparten una concepción exigente el Estado de Derecho -de hecho ello ha posibilitado los avances en el reconocimiento mutuo-, pero el Convenio pretende garantizar también el respeto a la diversidad, puesto que la observancia de los principios fundamentales del Derecho del Estado miembro requerido debe asegurarse, una vez concedida, durante la práctica de la audición, misión que corresponde a la autoridad judicial interna del Estado requerido que ha de estar presente en la misma, por más que la audición deba ser efectuada directamente por la autoridad judicial del estado requirente o bajo su dirección, con arreglo a su Derecho interno.

Naturalmente, la solicitud deberá motivarse en referencia a las exigencias de inoportunidad o imposibilidad de la comparecencia de la persona a oír. Ello no debe resultar dificultoso a tenor del significado de estos términos y de la regla de que la valoración de su 
concurrencia corresponde al Estado requirente por cuanto si bien éste debe comunicar los motivos de su solicitud dispone de plena libertad para valorar cuáles son las circunstancias pertinentes- por más que tenga que referir las razones al Estado requerido. El Estado requerido, pues, no debe cuestionar ni entrar en la valoración de la concurrencia de la inoportunidad o imposibilidad. No ha de ejercer control alguno de este tenor. Las tentaciones en este sentido deben ser desterradas.

El Informe explicativo apunta que "el concepto de "oportuno" podría aplicarse en los casos en los que el testigo sea especialmente joven, de edad avanzada o no goce de buena salud, mientras que el concepto de "posible" se aplicaría, por ejemplo, en los supuestos en los que el testigo corra un grave riesgo si comparece en el Estado miembro requirente". La referencia a la inoportunidad de la comparecencia personal abre una amplia espita a la justificación de la práctica de la videoconferencia, que trasluce una orientación claramente abierta y favorable a su utilización $y$ se traduce en un extenso margen de discrecionalidad de cara a la posibilidad de solicitarla. Por otra parte, la alusión a la imposibilidad tampoco implica la necesidad de la concurrencia de un impedimento absoluto al desplazamiento y comparecencia de la persona que debe ser oída en el proceso penal existente en el territorio del Estado requirente de la asistencia. El informe contempla, a título de mero ejemplo, el supuesto de que el testigo corra un riesgo grave si comparece, pero cabe concretar aún más e incluso imaginar otros supuestos ${ }^{6}$.

Junto a la indicación del motivo por el que no es oportuna o posible la comparecencia, la solicitud deberá informar sobre el nombre de la autoridad judicial y de las personas encargadas de efectuar la audición.

La autoridad judicial del Estado miembro requerido debe enviar una citación a la persona de que se trate con arreglo a los procedimientos establecidos en su Derecho Nacional. Testigos, víctimas y peritos tienen obligación de someterse a la videoconferencia -no es preciso su consentimiento-, así como de comparecer, declarar y ser

6 En esta línea debe tenerse muy en cuenta lo que poco después se dispuso en la Decisión-marco del Consejo, de 15 de marzo de 2001, relativa al estatuto de la víctima en el proceso penal, que alumbrada en el marco de refuerzo del denominado "cuarto proceso de integración", se preocupó por establecer líneas fundamentales de aproximación normativa dentro de los Estados miembros de la Unión Europea en materia de respeto y reconocimiento de los derechos de las víctimas, y, tras resaltar -art. 5- la necesidad de reducir las dificultades de comunicación que puedan afectarles, y proclamar sus derechos -art 8- a la protección frente al riesgo grave de represalias o de perturbación en su vida privada, a evitar el contacto con el acusado y a testificar en condiciones de seguridad y tranquilidad a través de medios compatibles con los principios fundamentales de los derechos nacionales, estableció, en su art. 11, la obligación de los Estados de paliar las dificultades derivadas del hecho de la residencia de la víctima en otro Estado, recurriendo "en la mayor medida posible, para la audición de víctimas residentes en el extranjero, a las disposiciones sobre videoconferencia y conferencia telefónica previstas en los arts. 10 y 11 del Convenio relativo a la asistencia judicial en materia penal entre los Estados miembros de la Unión Europea, de 29 de mayo de 2000". En dicha medida, constituye un importante elemento de exégesis de los "conceptos jurídicos indeterminados" integrados en los conceptos de inoportunidad o imposibilidad de la comparecencia. 
veraces, aplicándose en caso de incumplimiento de estas obligaciones su legislación nacional como si actuasen en un procedimiento nacional. Sobre las dispensas de declarar, se establece una especie de tercera fuente normativa (integrada por la suma de ambas legislaciones, la del Estado requirente y la del Estado requerido) para este concreto aspecto. Corresponderá a la autoridad judicial que efectúe la audición determinar en qué casos puede alegarse dicha dispensa. Las autoridades judiciales competentes deberían consultarse en relación con las alegaciones de dispensa de declarar en las audiciones. Las autoridades competentes de ambos Estados deberán convenir, cuando sea necesario, la adopción de medidas para garantizar la protección de las personas que deban ser oídas. La audición es efectuada directamente -o bajo su dirección- por la autoridad judicial y conforme al Derecho interno del Estado requirente, lo que no es sino una concreción de la regla general del art. 4 del Convenio 2000. Sin embargo, hay que tener presentes las facultades de la autoridad judicial interna del Estado requerido, que ha de estar presente (en su caso asistida por un intérprete), identificar a la persona que deba ser oída (quien también en su caso estará asistida por intérprete) y adoptar medidas tendentes a garantizar en todo momento de su práctica el respeto de los principios fundamentales de su Derecho interno. En todo caso la persona que deba ser oída mediante videoconferencia no debe tener menos derechos que si participara en una audiencia que tuviera lugar en el Estado miembro requirente.

Encuantoal reflejodocumentaldela prácticadelavideoconferencia, se establece que la autoridad judicial del Estado miembro requerido debe levantar acta de la declaración, en que se indicarán la fecha y lugar de la audición, la identidad de la persona oída, la identidad y calidad de cualesquiera otras personas del Estado miembro requerido que hayan participado en la audición, las prestaciones de juramento, en su caso, y las condiciones técnicas en las que se haya tomado la declaración. No obstante, dada la necesidad de garantizar la protección de las personas implicadas, incluidos los participantes en el Estado miembro requerido distintos de la persona que deba ser oída, los Estados miembros que intervengan podrán, de conformidad con su Derecho interno, aprobar disposiciones específicas relativas al acta. A tales efectos podría darse el caso, por ejemplo, de que no se registraran en el acta los nombres de determinadas personas presentes en el Estado miembro requerido con ocasión de la audición, indicándose únicamente, si procediese, las funciones de dichas personas. La autoridad competente del Estado miembro requerido transmitirá dicho documento a la autoridad competente del Estado miembro requirente.

En cuanto a los costes, salvo que el Estado miembro requerido renuncie a la devolución total o parcial de los costes, el Estado miembro requirente devolverá al Estado miembro requerido los 
gastos de establecimiento de la videoconexión, los costes relacionados con el servicio de videoconexión en el Estado miembro requerido, la retribución de los intérpretes que éste suministre y las dietas de testigos y peritos, así como sus gastos de viaje en el Estado miembro requerido.

\section{B) Si la solicitud se refiere a la audición de acusados}

En cambio, los Estados conservan libertad de decisión (incluso pueden hacer una declaración general de que no accederán solicitudes, aunque pueden retirarla en cualquier momento) y, en cualquier caso, para su práctica se requiere el consentimiento previo de los inculpados. El término acusado empleado en el texto español del Convenio no debe ser interpretado estrictamente -con parámetros nacionales- como persona contra la que existe un escrito de acusación. El propio Informe Explicativo se refiere al mismo concepto con la expresión "personas inculpadas". En este sentido parecen más afortunados, aunque quizás tampoco resulten muy respetuosos con la doctrina procesal penal más exquisita, los términos que emplea el artículo 9 del posterior Segundo Protocolo Adicional al Convenio Europeo de Asistencia Judicial en materia penal (Estrasburgo 8 de noviembre de 2001): acusados o sospechosos. En tal concepto, habría, por tanto, que incluir a aquellos contra los que se pretenda derivar una responsabilidad penal en el marco de un proceso -cualquiera que sea la fase- de naturaleza criminal. Esta es, además, la interpretación más favorable para los afectados pues el nivel de exigencias -empezando por la necesidad de su consentimientoy de garantías será mayor para los mismos.

La discrecionalidad de los Estados requeridos para acceder a la solicitud obligará, en primer lugar, a un esfuerzo de motivación sobre la necesidad y pertinencia de la medida. Naturalmente las autoridades competentes del Estado miembro requirente deberán efectuar una reflexión previa sobre las razones que motiven una preferencia por la videoconferencia respecto de otras posibilidades, como, por ejemplo la del "traslado temporal de detenidos con fines de investigación" regulada en el artículo 9 del Convenio o en relación con la toma de declaración o los traslados similares y las detenciones o entregas que posibilita la "euroorden" -orden de detención y entrega europea-, a través las correspondientes implementaciones nacionales de la Decisión Marco del Consejo (2002/584/JAI), de 13 de junio de 2002, relativa a la orden de detención europea y a los procedimientos de entrega entre Estados miembros -lo que no resultará difícil a la vista de su menor impacto sobre derechos individuales, su menor coste, su mayor agilidad y sus posibilidades de más rápida práctica- ${ }^{7}$.

7 En el supuesto de que se prevea la negativa del Estado o del inculpado (lo que no tiene por qué suceder frecuentemente si la previsión inminente es el recurso a la euroorden), entiendo 
En caso de consentimiento positivo, el acuerdo entre los Estados regirá la decisión y la forma de ejecución de la videoconferencia, pero ésta queda supeditada a la legislación nacional de los Estados miembros y ha de ser conforme con el $\mathrm{CEDH}^{8}$, así como con otros instrumentos internacionales pertinentes. A tenor de lo dispuesto en el apartado 9 del artículo 10 del Convenio 2000, los Estados implicados podrán aplicar las reglas de lo establecido para los testigos o peritos, pero sólo si lo consideran oportuno y previo acuerdo, de manera que éste podrá elevar el nivel de las exigencias establecidas en los apartados 1 a 8 . ¿Podrá rebajarlo? Entiendo que no, al menos en cuanto a sus precisiones esenciales. El propio carácter restrictivo de la posibilidad así parece orientar una línea de condiciones mínimas. En cualquier caso, la expresa referencia al CEDH implica un mínimo común denominador en materia de garantías de obligada observancia para Estado requirente y Estado requerido.

La regulación supranacional positivizada en la Unión Europea en el convenio 2000 se ha erigido en un elemento inspirador de otros instrumentos internacionales en el marco paneuropeo e iberoamericano.

En el marco de los Estados miembros del Consejo de Europa, se regula el uso de la videoconferencia a través de lo dispuesto en el art. 9 del Segundo Protocolo Adicional al Convenio Europeo de Asistencia Judicial en materia penal de 1959 (hecho en Estrasburgo 8 de noviembre de 2001) ${ }^{9}$ con una coincidencia casi total con el Convenio 2000 de la Unión Europea, lo que, sin duda, tiene su razón en un patente deseo de concordancia entre ambos instrumentos. En consecuencia, mutatis mutandi, pueden reproducirse muchas de las consideraciones ya efectuadas a excepción -lógicamente- de las alternativas y complementos que posibilitan las Decisiones Marco alumbradas en el seno de la Unión Europea.

Estos antecedentes europeos han sido tenidos muy en cuenta en la regulación contenida en el Convenio Iberoamericano sobre el uso de la videoconferencia en la Cooperación Internacional entre Sistemas de Justicia, hecho en Mar de Plata, Argentina, el 3 de diciembre de 2010 y en vigor desde el 17 de julio de 2014, así como el Protocolo Adicional al mismo relacionado con los costos, régimen lingüístico y remisión de solicitudes, firmado en la misma fecha y lugar (en vigor desde el 24 de agosto de 2016), cuya ratificación ha sido ya efectuada por seis países (Ecuador, España, México, Panamá, República Dominicana y Costa Rica) de los trece inicialmente firmantes.

que resultará preferible acudir directamente a la opción de utilización del mecanismo de la euroorden -naturalmente, si resulta aplicable en las relaciones entre los Estados implicados-. 8 Convenio Europeo de 1950 para la protección de los derechos humanos y de las libertades públicas.

9 Destinado a mejorar y completar el Convenio Europeo de Asistencia Judicial en materia penal, hecho en Estrasburgo el 20 de abril de 1959, así como su Protocolo Adicional de 17 de marzo de 1978. 
Este convenio tiene la virtualidad de erigirse en un instrumento de indudable utilidad también entre los países integrantes de MERCOSUR -donde precisamente persiste la idea de que a la integración económica debe acompañar una paralela integración jurídica- como medio concreto de fortalecer y agilizar la cooperación judicial mutua civil, comercial y penal en este marco y optimizar los recursos materiales del Sistema de Justicia, complementando en el área criminal las disposiciones de la Convención Interamericana sobre Asistencia Mutua en Materia Penal de 1992 y el Protocolo de San Luis sobre Ayuda Mutua en Asuntos Penales de 1996. No obstante, en la actualidad sólo un país del MERCOSUR ${ }^{10}$, concretamente Argentina, lo ha aprobado por Ley N ${ }^{\circ} 27162$ del 15 de julio de 2015 publicada en Boletín Oficial 29 de julio de 2015, aunque se encuentra pendiente -al tiempo de redactar estas líneas- el depósito del instrumento de ratificación.

Dicho convenio, aplicable subsidiariamente respecto de otras obligaciones internacionales de las Partes, entiende (artículo $2^{\circ}$ ) por "videoconferencia", en el ámbito de este convenio, un sistema interactivo de comunicación que transmita, de forma simultánea y en tiempo real, imagen, sonido y datos a distancia de una o más personas que presten declaración, ubicadas en un lugar distinto de la autoridad competente, para un proceso, con el fin de permitir la toma de declaraciones en los términos del derecho aplicable de los Estados involucrados, y dispone que, a sus efectos, su empleo procederá (artículo $3^{\circ}$ ) cuando no contradiga el derecho nacional de las Partes; medie una solicitud concreta e individualizable, remitida por autoridad competente del Estado requirente; sea aceptado por autoridad competente de la Parte requerida; y sea técnicamente realizable, indicando (artículo $4^{\circ}$ ) que si la autoridad competente de una Parte requiere examinar a una persona en el marco de un proceso judicial, en calidad de parte, testigo o perito, o en diligencias preliminares de investigación, y ésta se encuentra en otro Estado, podrá solicitar su declaración por videoconferencia por considerar esta herramienta conveniente, incluyendo su solicitud la identificación de la autoridad requirente, el número de referencia del proceso, el nombre y cargo de la autoridad que dirigirá la diligencia y, de ser procedente el nombre de las partes involucradas en el proceso y sus representantes; la naturaleza, el objeto del proceso y la exposición de los hechos; la descripción de lo que se pretende conseguir con la diligencia; el nombre y dirección de las personas a oír; la referencia a un eventual derecho de objeción a declarar, según se recoge en el derecho de la Parte requirente; la referencia a las eventuales consecuencias de la negativa a declarar, en los términos del derecho de la Parte requirente; la eventual indicación de que el testimonio deberá ser hecho bajo juramento o promesa; y cualesquiera otras referencias previstas conforme el derecho

10 También lo signaron en su momento inicial Brasil y Paraguay. 
de la Parte requirente o de la Parte requerida o que se revelen útiles para la realización de la videoconferencia.

Las normas de desarrollo de la videoconferencia (artículo $5^{\circ}$ ) parten de que el examen se realizará directamente por la autoridad competente de la Parte requirente o bajo su dirección, en los términos señalados en su derecho nacional (al igual que en el Convenio 2000); y establecen que la diligencia se realizará con la presencia de la autoridad competente del Estado requerido y, si fuera necesario, de una autoridad del Estado requirente, acompañadas, de ser el caso, por intérprete; que la autoridad requerida ha de identificar la persona a examinar; que las autoridades intervinientes, en caso necesario, podrán aplicar medidas de protección a la persona a examinar; que, a petición de la Parte requirente o de la persona a examinar, la Parte requerida le proveerá, en caso necesario, de la asistencia de intérprete.; y que la sala reservada para la realización de la diligencia por sistema de videoconferencia deberá garantizar la seguridad de los intervinientes, y preservar la publicidad de los actos cuando ésta deba ser asegurada.

En cuanto al examen de procesados o imputados (artículo $6^{\circ}$ ) resultan aplicables las disposiciones anteriores, de conformidad con el derecho interno de cada Parte, y deben respetarse todos los derechos y garantías procesales, en especial el derecho a contar con asistencia letrada. Sin embargo, como en el sistema europeo, las Partes pueden declarar que no aplicarán el convenio al examen por videoconferencia de procesados o imputados.

Sobre el reflejo documental del examen por videoconferencia (artículo $7^{\circ}$ ) se dispone que la autoridad que realiza el examen en la Parte requerida levantará, una vez terminada la videoconferencia, un acta -que será remitida a la autoridad competente de la Parte requirente- donde conste la fecha y el lugar de la diligencia, la identidad y firma de la persona examinada, la identidad, calidad y firma de todas las otras personas que hubieren participado, las eventuales prestaciones de juramento o promesa y las condiciones técnicas en que transcurrió la misma, sin perjuicio de que en dicha acta se tomen aquellas previsiones en aras de garantizar las medidas de protección que se hubieren dispuesto.

Especialmente interesante resulta que para facilitar y agilizar la preparación y el desarrollo de las audiencias por videoconferencia previstas en el Convenio, cada Parte deberá indicar uno o más puntos de contacto, concretamente a través de la disponibilidad de contactos telefónicos y de correo electrónico, que detenten la capacidad técnica necesaria para asegurar o cooperar en la ejecución de una videoconferencia entre las autoridades de las Partes, lo que supone una traslación del sistema de puntos de contacto de las redes judiciales de cooperación (Red Judicial Europea e Iber-RED) como facilitadores e intermediarios activos del empleo de esta concreta herramienta técnica 
en términos de auxilio judicial.

Entre las declaraciones a efectuar (artículo $9^{\circ}$ ) el Convenio prevé que al proceder a la notificación de la oportuna ratificación, aceptación o aprobación cada Parte debe efectuar una declaración mediante la cual indicará: a) las autoridades nacionales competentes para la aplicación del presente Convenio y sus contactos (dirección postal, contacto telefónico y correo electrónico), debiendo actualizarlos en caso de alteración, así como los contactos previstos en el artículo $8^{\circ}$, si fuesen distintos; b) las eventuales condiciones bajo las cuales se podrá aplicar el presente Convenio a las audiencias por videoconferencia de imputados, salvo que la Parte haya efectuado la declaración de que no las acepta para éstos; y c) las eventuales especificidades nacionales que puedan ser relevantes para la buena ejecución del Convenio. En cualquier caso, las declaraciones emitidas podrán ser total o parcialmente alteradas en cualquier momento, según el mismo procedimiento de notificación.

Por su parte, el Protocolo Adicional regula los costos de la ejecución de la videoconferencia (artículo $1^{\circ}$ ), disponiendo que el costo del establecimiento de la conexión, los gastos relacionados con la realización de la videoconferencia en la Parte requerida, la remuneración de intérpretes eventualmente requeridos y las compensaciones pagadas a testigos y peritos, así como sus gastos de desplazamiento en la Parte requerida, serán asumidos directamente o reembolsados por la Parte requirente a la Parte requerida, a menos que esta renuncie al reembolso de la totalidad o de parte de dichos gastos.

El régimen lingüístico previsto contempla (artículo $2^{\circ}$ ) que las solicitudes de realización de una audiencia por videoconferencia remitidas por las autoridades de la Parte requirente a la Parte requerida podrán ser formulados en lengua española o en lengua portuguesa, independientemente de la lengua oficial de la Parte requerida o de la Parte requirente, pero establece la salvedad de que una Parte puede aceptar recibir únicamente solicitudes en una determinada lengua haciendo una declaración en ese sentido.

La remisión de solicitud de videoconferencia (artículo $3^{\circ}$ ) podrá transmitirse por cualquier medio electrónico que permita dejar constancia escrita de la transmisión, en condiciones que posibiliten a la Parte requerida establecer su autenticidad, pero cuando no sea posible constatar esta autenticidad, se podrá adelantar la solicitud por dichos medios y se formalizará posteriormente por solicitud de la autoridad requerida.

\section{VIDEOCONFERENCIA Y DEBIDO PROCESO}

Como puede comprobarse, la videoconferencia es una herramienta tecnológica que, por su utilidad como medio de auxilio para la actividad judicial y fiscal, es admitida en numerosos ordenamientos internos y en 
los más modernos instrumentos internacionales.

Sin embargo, su empleo no ha dejado de suscitar cierta polémica -aunque cada vez más decreciente- en relación con la satisfacción de las exigencias y garantías derivadas del necesario respeto al debido proceso. De hecho, no han faltado doctrina e incluso documentos emanados de instituciones del sistema judicial que han cuestionado su uso por perturbar e infringir los principios que rigen el proceso penal. Sin ir más lejos, la Instrucción FGE núm. 1/2002 ${ }^{11}$ llegó a afirmar que "los principios de publicidad, oralidad, inmediación y contradicción se ven sin duda afectados por la celebración de un juicio oral en materia penal por videoconferencia". Aunque afectar no es exactamente y en términos generales sinónimo de vulnerar o infringir, sino de causar un efecto en algo, no cabe duda de que una de las acepciones que le otorga el diccionario RAE es la de menoscabar, perjudicar, o influir desfavorable o negativamente. $Y$ es innegable que en esta idea se encuentra el fundamento de la salvaguarda que habitualmente se efectúa en instrumentos internacionales de que su uso es admisible siempre que no sea contrario a los principios fundamentales de Derecho interno de un Estado. Lo que sucede, no obstante, es que, al margen de las tradiciones jurídicas distintas asentadas en los diversos países, en lo que al proceso penal propio de un Estado de Derecho respecta, existen unos estándares compartidos de respeto a las garantías que han sido en buena medida uniformizados, normativa y jurisprudencialmente, a partir de las disposiciones de instrumentos jurídicos internacionales de carácter emblemático en materia de Derechos Humanos, tales como, a nivel mundial, la Declaración Universal de Derechos Humanos de 1948 (DUDH) y el Pacto Internacional de Derechos Civiles y Políticos de 1966 (PIDCyP), o, a nivel regional, como el Convenio Europeo de Derechos Humanos de $1950(\mathrm{CEDH})$ y la Convención Americana sobre Derechos del Hombre de 1969 (CADH).

Cierto es que el derecho fundamental al debido proceso reconocido en numerosos preceptos del acervo internacional en materia de Derechos Humanos, tales como el art. 10 DUDH, el art. 6.1 CEDH, el art. 14.1 PIDCyP y el art. $8 \mathrm{CADH}$, se caracteriza por su contenido complejo, comprensivo de todo un haz de derechos, instituciones y principios específicos, interrelacionados entre sí, con unidad de sentido y objetivo común, cuyo fundamento esencial se halla en rodear al proceso de garantías suficientes de equidad y justicia, y que puede identificarse con las nociones internacionales de derecho a "un proceso regular" y/o a "un juicio justo y equitativo". Dentro de ese haz

11 Fiscalía General del Estado del Reino de España. Aunque este documento -elaborado con cierta urgencia- fue claramente restrictivo en relación con el uso de la videoconferencia en juicios orales, la propia Fiscalía General rectificó pronto su postura en la posterior Instrucción 3/2002 en la que proclamó que la regla general para la celebración de actos procesales mediante videoconferencia era la posibilidad. 
confluyen categorías garantistas (juez legal, competente, independiente e imparcial), principios y derechos matrices (igualdad de armas y contradicción, en íntima conexión con el derecho de defensa efectiva y el derecho a la prueba, y a la presunción de inocencia con prohibición de toma en consideración de la prueba ilícita) y principios instrumentales (publicidad, oralidad, inmediación, principio acusatorio), todo ello con fundamento en la necesidad de no llegar a un resultado del proceso penal sino en virtud de un juicio previo tras el desenvolvimiento de un proceso con todas las garantías.

Por consiguiente, no cabe duda de que los principios de publicidad, oralidad, inmediación y contradicción -esta última exigencia estructural del proceso penal que presenta una vinculación muy estrecha con el principio de igualdad de armas y el derecho de defensa, conformando un todo inescindible con ellos- resultan elementos integrantes fundamentales del debido proceso. Sin embargo, en cuanto a su "afección" por la videoconferencia cabe efectuar una serie de observaciones, que a mi juicio deben partir de dos reflexiones iniciales.

La primera es que, en términos generales, en cada fase de proceso y en función de lo que se pretenda del concreto acto desarrollado la intensidad de los principios exigibles como presentes pueden variar. Naturalmente no será lo mismo que estemos ante un acto de simple investigación desarrollado en fase de en una actuación preprocesal del fiscal, instrucción judicial -realizada o no bajo el secreto sumarial- o en una diligencia de prueba anticipada o preconstituida, o en una práctica de prueba ante el órgano jurisdiccional de enjuiciamiento.

La segunda es que, en mi opinión, los principios exigibles en cada uno de estos casos pueden ser respetados o no independientemente de lo que realmente supone la videoconferencia, de manera que el empleo del recurso técnico es inocuo per se respecto de determinados principios.

En definitiva, la publicidad, la contradicción y la oralidad necesarias en cada caso no quedarían afectadas por el empleo de la videoconferencia sino por la forma en que se acuerde su práctica o se lleve a cabo su ejecución. Aseveración que es predicable respecto de la forma de práctica o ejecución de cualesquiera diligencias en las condiciones tradicionales sin empleo de medios tecnológicos.

Por detenernos en un ejemplo, el recurso tecnológico posibilita las mismas condiciones de publicidad inmediata o mediata, absoluta, relativa o restringida, que puede darse en cualquier desarrollo de un acto procesal. Basta con dar acceso a la asistencia personal y física de público en los distintos lugares donde se hallasen los puntos de conexión y asegurar un visionado y un volumen sonoro suficientes para la percepción pública para entender producido el acto en condiciones de publicidad absoluta. El derecho a ser juzgado mediante un proceso público no se ve mermado por ello. 
Lo mismo cabría decir respecto de la contradicción, lo importante es que se asegure la concurrencia e intervención de las partes en los actos que se desarrollen; que puedan efectuar preguntas, pedir precisiones y solicitar las aclaraciones que estimen oportunas, así como contradecir las argumentaciones contrarias con aportaciones propias. Tanto las disposiciones aplicables para el juicio oral, como las relativas a los actos desarrollados en fase preliminar de investigación o instrucción -estemos o no ante pruebas no reproducibles en el acto de juicio - pueden ser tan respetadas como en las formas tradicionales.

Y tampoco ofrece problemas acatar el principio de oralidad, de hecho, ésta es consustancial a la videoconferencia en cuanto instrumento de comunicación oral y visual. Pocas palabras hay que dedicar para justificar lo evidente.

Lo importante, en definitiva, es que en cada caso se respeten los principios básicos aplicables al supuesto que se contemple.

Así las cosas, las críticas que merecerían una mayor atención en la respuesta serían las referidas al respeto de los principios que rigen la adecuada relación entre el órgano jurisdiccional y lo que constituye objeto del proceso y muy específicamente la relación de inmediación. Básicamente expuesto, conforme al principio de inmediación la actividad desarrollada y especialmente la actividad probatoria "ha de transcurrir ante la presencia o intervención del órgano jurisdiccional encargado de pronunciar la sentencia", regla que rige todo el enjuiciamiento.

Quienes han cuestionado la validez procesal del uso de la videoconferencia aseguran que la inmediación no se da, pues no todos los actos tendrían lugar en presencia del órgano jurisdiccional. Pero ello a mi juicio constituye un desviado entendimiento de lo que significa la videoconferencia, que no es más que un medio técnico de auxilio que posibilita las facultades de percepción física del juzgador respecto de lugares distantes a su ubicación física -que no a su alcance sensorial-.

Como se expuso al inicio, este recurso tecnológico permite planos generales, seguimientos, planos cercanos, aplicaciones de zoom respecto de determinados detalles, etc. En esencia, la videoconferencia es un medio tecnológico que posibilita la comunicación a distancia con una percepción no sólo igual, sino puede asegurarse que mejor y mayor en cuanto a detalles que pueden darse en una vista oral con presencia física de todos los implicados. En realidad, la videoconferencia en nada empece u obstaculiza la mejor percepción sensorial, sino que más bien la facilita. El Juez de un órgano colegiado o unipersonal puede realizar todos los actos directos de intervención judicial previstos en los CPPs en las mismas condiciones de comunicación a tiempo real que en el juicio tradicional. En efecto, se puede preguntar al acusado sobre su conformidad o no, en su caso, con las solicitudes acusatorias y se pueden dirigir los debates en las mismas condiciones; la actividad probatoria 
se desarrolla con intervención y en presencia del titular o titulares del órgano jurisdiccional; ante éste se puede reproducir, en su caso y en condiciones de plena contradicción, la actividad investigadora realizada, y Ministerio Fiscal y las partes pueden interrogar, intervenir e informar sin mayor complicación, pudiendo, de preverlo la normativa procesal, el Juez o Tribunal dirigir las preguntas y pedir las aclaraciones que estime oportunas a acusado, testigos y peritos, a lo largo de las declaraciones, confesiones, testimonios, careos, exploraciones, informes, periciales, etc. que puedan tener lugar a lo largo de la vista, y finalmente conceder el derecho de última palabra al acusado y escuchar directamente sus afirmaciones.

Dado que el sistema de videoconferencia es bidireccional e interactivo, permite a los intervinientes su recíproca visión y audición en unidad de tiempo, e interactuar entre ellos. Lo ocurrido puede ser apreciado directamente por el Juez, Fiscal, partes y demás sujetos de modo análogo a lo sucedido respecto a quienes se encuentran físicamente en la sede judicial.

Ninguna violación se produce respecto de la regla que ordena que determinados actos procesales se realicen "ante" un Juez o Tribunal. E incluso cabría añadir que resultaría difícil entender que si no se cuestiona ya la validez de la valoración como prueba de una grabación sonora o audiovisual de un hecho que ha tenido lugar en un tiempo anterior y en un sitio distinto al de celebración de la vista y que en el juicio ha de ser reproducida también con empleo de medios técnicos similares (video y monitor o reproductor fonográfico), pueda cuestionarse que se dé validez a una declaración de un testigo o perito que se desarrolla con intervención directa de la autoridad jurisdiccional, en tiempo real y en su presencia sensorial. De hecho, si en relación al uso de videocámaras y el valor de sus grabaciones como diligencia de investigación se ha llegado a la conclusión de que éstas no suponen una prueba distinta a la percepción visual, y que en realidad sólo se perpetúa ésta por medios técnicos al quedar fijada un secuencia de imágenes y sonidos, resulta poco comprensible no reconocer que la videoconferencia posibilita una percepción visual y sonora directa por el Juzgador y los demás intervinientes en la misma y que es ésta la esencia de la inmediación. Parafraseando el dicho de que "una imagen vale más que mil palabras", habría que decir que "participar en una videoconferencia convence más que mil argumentos escritos". Me alegra coincidir con numerosos Jueces y Magistrados que tras intervenir profesionalmente dirigiendo videoconferencias para posibilitar testificales o periciales han perdido todas sus reticencias por la "aventura". Con esta experiencia han comprobado que sus condiciones de inmediación no han sufrido merma alguna.

Por demás, defender que el equipo de videoconferencia debe 
ser rechazado porque extiende la percepción directa de los sentidos del juzgador a lugares que no alcanzaría por sus medios naturales de percepción, esencialmente vista y oído, tiene en el fondo la misma base que propugnar que el Juzgador debe desprenderse de sus anteojos o de su audífono para ubicarse en condiciones de mayor inmediatez.

La conclusión, por tanto, es que la videoconferencia no choca frontalmente con ningún principio fundamental del proceso penal y, por ende, no existen obstáculos insalvables desde la perspectiva del debido proceso. Ello, sin embargo, no quiere decir que su empleo deba ser indiscriminado y carente de fundamento. En mi opinión, precisamente por su capacidad de incidencia sobre principios procesales estructurales del sistema penal que se erigen en auténticos derechos fundamentales del sometido al proceso penal, deben concurrir los tradicionales requisitos de necesidad, adecuación y proporcionalidad exigibles conforme a la doctrina general de restricción en materia de derechos fundamentales. Por el requisito de la necesidad, es preciso tener en cuenta y fundamentar cómo no existen otras medidas adoptables que con igual o parecida eficacia puedan conducir a los mismos resultados. Por el presupuesto de la idoneidad resulta necesario considerar y motivar suficientemente cómo el uso de este avance tecnológico es adecuado para la consecución del fin legítimo perseguido, conduciendo naturalmente al mismo. Por la exigencia de proporcionalidad hay que plantearse la aptitud de la videoconferencia para la obtención del fin perseguido en cada supuesto, contemplando la relación razonable entre el resultado buscado y las renuncias a las condiciones normales de celebración del acto que resultan necesarias para lograr ese objetivo. Hay que valorar ya desde el inicio la gravedad del hecho o de la situación y su suficiencia para justificar la aplicación de este recurso técnico. En definitiva, su práctica debe estar suficiente y expresamente motivada en razones de este tenor.

Ésta es la perspectiva con la que en mi opinión debe ser analizada la concreta utilización de la videoconferencia ante cualquier acto preprocesal o procesal penal. Naturalmente los niveles de exigencia pueden ser variados en función de quién sea el sujeto o interviniente procesal y cuál sea la naturaleza del acto. La ponderación debe presidir la aplicación de la videoconferencia analizando si en el caso concreto y para el específico acto procesal contemplado concurren los presupuestos suficientes y se aseguran las condiciones exigibles para la celebración con escrupuloso respeto de los derechos fundamentales de los implicados en el proceso penal.

\section{CONCLUSIÓN}

La videoconferencia se ha revelado como un medio tecnológico de evidente utilidad como herramienta técnica de auxilio a la actividad 
procesal en el ámbito del proceso penal y ha obtenido un amplio reconocimiento normativo a estos efectos tanto en los más modernos ordenamientos nacionales como en los instrumentos jurídicos internacionales de cooperación judicial internacional elaborados en los albores del presente siglo. Su compatibilidad con los principios fundamentales que rigen el debido proceso es total y no cabe discutirla más allá de exigir que se produzca en casos justificados y en las debidas condiciones para asegurar el respeto ineludible a las exigencias derivadas del derecho al debido proceso.

Por consiguiente, es razonable que los Estados que aún no la contemplan en el proceso penal para su uso interno nacional y/o su empleo en el ámbito de la cooperación judicial internacional se esfuercen en adaptar sus legislaciones y compromisos internacionales para luchar contra la delincuencia nacional y transnacional. Los ciudadanos a los que sirve el Sistema de Justicia así lo merecen y parece evidente que los Estados del MERCOSUR pueden beneficiarse del valor añadido que su reconocimiento normativo y empleo práctico aportan.

Una vez más, debe recordarse: la celebración del proceso en el siglo XXI no se puede pretender con los usos del siglo XX.

\section{REFERENCIAS BIBLIOGRÁFICAS}

CONFERENCIA DE MINISTROS DE JUSTICIA DE LOS PAÍSES IBEROAMERICANOS. Convenio Iberoamericano sobre el uso de la videoconferencia en la Cooperación Internacional entre Sistemas de Justicia, Mar de Plata, Argentina, el 3 de diciembre de 2010.

CONFERENCIA DE MINISTROS DE JUSTICIA DE LOS PAÍSES IBEROAMERICANOS. Protocolo Adicional al mismo relacionado con los costos, régimen lingüístico y remisión de solicitudes, firmado en la misma fecha y lugar (en vigor desde el 24 de agosto de 2016).

CORTE PENAL INTERNACIONAL. Estatuto de la Corte Penal Internacional aprobado en Roma el 17 de julio de 1998.

ESPAÑA. Ley 1 de marzo de 1997.

ESPAÑA. Ley de 15 de noviembre de 2001.

ESPAÑA. Ley de 17 de enero de 1998.

ESPAÑA. Ley de 17 de junio de 1999.

ESPAÑA. Ley de Cooperación Judicial Internacional 144/99.

ESPAÑA. Ley N 11 de 7 de enero de 1998.

ESPAÑA. Ley N ${ }^{\circ} 27162$ del 15 de julio de 2015

ESPAÑA. Ley No 367 de 5 de octubre de 2001. 
ESPAÑA. Ley Orgánica 13/2003.

ESPAÑA. Ordenanza de 20 de agosto de 1998.

ESPAÑA. Segundo Protocolo Adicional al Convenio Europeo de Asistencia Judicial en materia penal, Estrasburgo, 8 de noviembre de 2001.

MERCOSUR. Protocolo de San Luis sobre Ayuda Mutua en Asuntos Penales de 1996.

UNIÓN EUROPEA. Convenio Europeo relativo a la Asistencia Judicial en materia penal entre los Estados miembros de la Unión, 2000.

UNIÓN EUROPEA. Decisión Marco del Consejo (2002/584/JAI), de 13 de junio de 2002.

\section{RESUMEN BIOGRÁFICO}

Jesús José Tirado Estrada es Teniente Fiscal ante el Tribunal Constitucional y Doctor en Derecho. Con más de 32 años de experiencia profesional como Fiscal, es experto en cooperación judicial internacional (antiguo miembro de RJE e Iber-RED), así como en el uso de nuevas tecnologías en el proceso penal. 